\section{REPORT OF A CASE OF PARALYSIS OF THE BLADDER}

\section{ILLUETRATING 'THE IMPORTANCE OF CATHETERIZATION BEFORE OPERATION}

\section{H. J. RELIHAN, M.D., AND J. SIMON, M.D.} SANBORN, IOWA

In this case of paralysis of the bladder the patient was operated on under the diagnosis of ovarian cyst with twisted pedicle complicated by pelvic infection. The condition followed normal labor and delivery, and shows the importance of catheterization before operation.

Patient.-Married woman, aged 30, mother of three normal children; previous history negative; in the second stage of labor when first seen. A normal living ehild was delivered without the use of forceps and without laceration of the mother's tissnes. Delivery of the placenta was normal. For the first six days after delivery the patient's condition was normal. On the sixth day, the uterus was six finger's-breadths above the pubis. The urine was examined and found normal. The patient felt well. On the seventh day, the temperature was $102 \mathrm{~F}$., and pulse was 120 . The patient complained of great abdominal pain, more especially on the right side. The abdomen at this time began to distend rapidly and in size simulated a six-months' pregnancy. The bowels were regular and a normal amount of urine was being passed though there was some irritability of the bladder. On the eighth day, the temperature was $103 \mathrm{~F}$. and the pulse 140 and poor in quality. All the symptoms pointed to puerperal sepsis except the dis. tention of the abdomen, especially the lower part. Pain at this time was only controlled by administration of $1 / 4$ grain of morphin sulphate as necessary. By this time the size of the abdomen resembled a full term pregnancy.

Examination.-This showed great abdominal distention, especially in the lower portion. Percussion showed a cyst or watery tumor in the median line, especially in the pelvis. It seemed to be of great size and a diagnosis was made of ovarian cyst with twisted pedicle accompanied by pelvic infection, and immediate operation was advised.

13lood Examination: White cells, 18,000; red cells, 5,000,000; hemoglobin, 90 per cent. Differential count showed: small mononuclears, 18 per cent.; large mo onuclears, 6 per cent.; eosinophils 2 per cent.; polymorphonuclears, 74 per cent.

Urine Examination: The urine was being passed every two to four hours in quantities of from 4 to 6 ounces. The reaction was alkaline. Otherwise it was normal.

Operation.-As the patient had been passing urine at regular intervals and had passed eight ounces just before the operation it was not thouglit necessary to catheterize her. An incision about 4 inches long was made in the median line. A large blue, thin-walled tumor presented which resembled in every way a cyst of ordinary character. A trocar was inserted and 3 gallons of urine were withdrawn. The fact that the tumor was not a cyst but the bladder was not recognized til lthe mine escaped through the trocar. The viscus was closed with No, 2 Chromic catgut, great care being exercised not to injure the inucosa. The abdominal incision was closed in the usual way and both wounds healed by primary union.

l'ostoperative History.-The ordinary treatment in any postoperative case was carried out, plus, of course, treatment of bladder symptoms. There was no complaint of pain. The patient was catheterized three hours after the operation and three times a day thereafter, the strictest antiseptic precautions being observed each time. After the fourth day, after the last eatheterization of the day, a few drops of silver nitrate solution were left in the urethra. Hexamethylenamin (urotropin) was given regularly. On the fiftl day as often happens after repeated catheterization, the bladder became infected. The patient had chills and the temperature rose from normal to $103 \mathrm{~F}$; ; the pulse was 138 . The kidneys also became infected. Analysis of the urine showed: color, dark cloudy; specific gravity, 1026; sugar, negative; albumin, negative; indican, piesent; bile, negative. Microscopic examination showed many motile bacteria, numerous crystals (calcium oxalate), granu- lar casts and blood-cells. There was also excess of mucous and triple phosphates. By the twelfth day the patient was in excellent condition and she was discharged well on the eighteenth day.

\section{A CASE OF ENTERITIS FROM TRICHOCEPH- ALUS DISPAR}

\section{B. N. WADE, M.D, CHICAGO}

Patient.-An Austrian woman, aged 22, entered the Cook County hospital suffering from an intractable anemia and it was not until after her stools had been examined that the etiologic factor was discovered. She had lived in Boston until four months prior to admission. She had worked as a laundress; never used alcoholics; fool was of poor quality; she ate in cheap restaurants. Fourteen months prior to admission the patient began to lose strength, and finally had to quit work; suffered with severe headaches, which were always in the occipital region. Her appetite was poor, and eating would nauseate her, and often caused vomiting, but she never vomited blood; had not vomited or even been nauseated for several months; the bowels had always been regular. The patient had had a slight bronchitis ever since the trouble began; had never been troubled with fainting spells or palpitation, although at times she became very weak and dizzy; on exertion, she would become short of breath. The patient had lost 50 pounds in weight. When the trouble first came on, the patient suffered a great deal from epistaxis, but had never lost any great amount of blood from this source; had complete amenorrhea since the beginning of the illness and during the time of the menstrual periods would often have nose-bleed. Previous to this the menstruation was normal. The patient stated that the muscles in her arms had pained ever since she took sick, and they were somewhat tender, and became stiff on exercising them. This myalgia was most severe at night. The patient also complained of a dull aching pain in the abdomen, especially in the splenic region, and said that it was always present; there was a drowsy feeling all the time. The patient had never felt this way until this trouble came on.

Physical Examination.-The patient appeared languid and apathetic; was pale and anemic; pulse and temperature were normal. The tongue was coated white, and the breath exceedingly foul. The chest and cardiovascular system were negative. There was some tenderness in the left epigastric region and over the descending colon; liver and spleen normal. On vaginal examination, there was extreme tenderness in the posterior fornix; rectum was somewhat tender. The stools were foul-smelling, greenish in color and watery in eonsistency. They contained many ova of the Trichocephalus dispar, which were of the characteristic brown oval forms with clear polar bodies. Each field contained four or five ova. After repeated examinations, the parasites themselves were found but once. There was no occult blood in the stools; small particles of undigested foods were present and mucus was also present to some extent.

Blood Examination.-Red cells, 3,100,000 per c.mm.; leuko cytes, 8,300 per c.mm.; hemoglobin, 80 per cent. The differential count showert an eosinophilia of 10 per cent.; the other cells were present in about normal percentage.

The urine showed the presence of indican; otherwise it was normal. The stomach contents were also normal.

Treatment.-Two weeks after the patient was put on thymol, gr. 2 , t. i. d., the ova completely disappeared from the stools. The bowels were kept open with calomel and Epsom salts, and an occasional colonic flushing was also given. The anemia was disappearing under the use of Fowler's solution and elixir, iron, quinin and strychnin.

My reasons for reporting this case are, first, to emphasize the importance of examination of the stools as a routine procedure, and especially in cases of anemii when no cause is evident; and second, because this is a disease which is either infrequent in this section, or one which is commonly overlooked. 